\title{
OBJETOS DA QUARENTENA: URGÊNCIA DE MEMÓRIA
}

\author{
Quarantine objects: urgency of memory
}

Objetos de la cuarentena: urgencia de la memoria

ISABELLA PERROTTA ${ }^{* *}$ LUCIA SANTA CRUZ ${ }^{I^{* *}}$

DOI: https://doi.org/10.1590/S2178-149420210206

'Escola Superior de Propaganda e Marketing - Rio de Janeiro (RJ), Brasil.

*Coordenadora do Mestrado Profissional em Gestão da Economia Criativa, Escola Superior de Propaganda e Marketing; designer, doutora em História Social e Bens Culturais, Centro de Pesquisa e Documentação de História Contemporânea do Brasil, Fundação Getulio Vargas (iperrotta@espm.br).

(D) http://orcid.org/0000-0002-7805-8443

"Escola Superior de Propaganda e Marketing - Rio de Janeiro (RJ), Brasil.

**Coordenadora-adjunta do Mestrado Profissional em Gestão da Economia Criativa, Escola Superior de Propaganda e Marketing; jornalista, mestre e doutora em Comunicação e Cultura, Universidade Federal do Rio de Janeiro.

(lucia.santacruz@espm.br)

(D) http://orcid.org/0000-0003-1007-2473

Artigo recebido em 29 de dezembro de 2020 e aprovado para publicação em 11 de março de 2021. 


\title{
RESUMO
}

Este artigo trata da urgência de construção de memória desencadeada pela pandemia de COVID-19. Compara-o com o momento da gripe espanhola quando as pessoas preferiram "esquecer de lembrar", referencia-se no movimento de valorização da memória e do testemunho nas sociedades ocidentais contemporâneas, e, utilizando o método documental, apresenta o projeto colaborativo Objetos da Quarentena, cuja proposta é aprofundar a discussão sobre o papel dos objetos na intermediação das relações humanas e construção da memória em tempos de isolamento social. A análise preliminar aponta que objetos escrevem e inscrevem nossas memórias, enquanto narramos esse tempo de confinamento.

PALAVRAS-CHAVE: Urgência de memória; Cultura material; COVID-19; Quarentena; Nostalgia; Testemunho.

\begin{abstract}
This article deals with the urgency of building memory triggered by the pandemic of COVID-19. It compared it with the moment of the Spanish flu when people preferred to "forget to remember", it refers to the movement of valuing memory and testimony in contemporary Western societies, and, using the documentary method, presents the collaborative project Objetos da Quarentena, whose proposal is to deepen the discussion on the role of objects in the intermediation of human relationships and the construction of memory in times of social isolation. The preliminary analysis points out that objects write and inscribe our memories, while we narrate this time of confinement.
\end{abstract}

KEYWORDS: Urgency of memory; Material culture; COVID-19; Quarantine; Nostalgia; Testimony.

\section{RESUMEN}

Este artículo aborda la urgencia de construir memoria que desencadenó la pandemia de COVID-19. Lo compara con el momento de la gripe española cuando la gente prefería "olvidar recordar", se hace referencia en el movimiento para valorar la memoria y el testimonio en las sociedades occidentales contemporáneo, y, utilizando el método documental, presenta el proyecto colaborativo Objetos da Quarentena, cuya propuesta es profundizar la discusión sobre el papel de los objetos en la intermediación de las relaciones humanas y la construcción de la memoria en tiempos de aislamiento social. El análisis preliminar señala que los objetos escriben e inscriben nuestros recuerdos, mientras nosotros narramos este tiempo de encierro.

PALABRAS CLAVE: Urgencia de la memoria; Cultura material; COVID-19; Cuarentena; Nostalgia; Testimonio. 


\section{INTRODUÇÃO}

s pestes pareciam ter ficado na idade das trevas. A modernidade impusera grandes
verdades por meio da ciência, da tecnologia, do planejamento urbano, da crença no Estado, prometendo segurança e bem-estar. Em tempos modernos, o século XXI era um futuro distante, idealizado e robotizado. Inverossímil ser derrotado por um vírus desconhecido e invisível. Mas é chegado um novo tempo de pandemia. Mudanças significativas nos hábitos de trabalho, ensino, lazer e convivência são impostas. É tempo de contar o tempo de outra forma. A pandemia ainda não acabou, mas os primeiros momentos da COVID-19 foram tão intensos que, passados alguns meses, várias pessoas se referem à experiência vivida em março e abril de 2020 como "no tempo da pandemia...".

Mais tempo em casa. Mais tempo no computador e na internet, mais tempo sentados. Mais tempo para fazer mais coisas, ou menos tempo disponível? Algumas pessoas (apenas algumas) talvez tenham tido a oportunidade de aumentar a qualidade do seu tempo no período de quarentena. Contudo, é certo que antes o tempo Chronos (externo e quantitativo) tinha um valor maior do que o tempo Kairós (interno e qualitativo). Agora, pelo menos, passamos a valorizar mais a qualidade de ser e viver.

Entre os efeitos do isolamento e do luto, veio - de imediato - a necessidade de construção da memória desse tempo. Nunca "tantos filósofos escreveram tão rapidamente acerca de um acontecimento quanto no caso do COVID-19. Desde o começo da pandemia, textos são publicados quase toda semana e divulgados ligeiramente" (Duarte P., 2020: 112). Nunca se coletaram tantos relatos, imagens e objetos do tempo presente.

Em grande parte, o volume crescente de narrativas sobre o momento atual deve-se também à presença das tecnologias de informação e comunicação, que permitem não só a produção de conteúdo numa escala quase industrial, como também possibilitam a sua distribuição a grandes grupos de pessoas e o seu consumo de variadas formas.

Operando como veículos de difusão de conteúdo elaborados por diferentes atores (empresas, pessoas comuns, artistas, influenciadores digitais, entre outros), as plataformas de redes sociais, como WhatsApp, Facebook e Instagram, transformaram-se, nessa conjuntura, em espaços de integração. Ligam grupos e servem de palcos para espetáculos e de academia. Circulam vídeos e imagens em movimento quando tudo parece parado do lado de fora. São janelas para o mundo. Telas que exibem rotinas de trabalho, lives de músicos, momentos em família, pelas quais se pode aprender a cozinhar durante a pandemia ou montar uma "festa" virtual, além de fazer protestos. Mostram o novo cotidiano de quem está confinado, visualizado por outros também em restrição de mobilidade. Fenômeno da contemporaneidade, expõem a intimidade 24 horas por dia, num esforço para estabelecer uma normalidade mesmo quando a vida parece 
estar em suspenso. Este empenho coletivo de exposição que, ao mesmo tempo, se esforça por narrar esse período extremo da sociedade acaba por promover certa aceitação do novo normal, desta vida permeada por dispositivos que nos mostram o que há lá fora.

Lilia Schwarcz - para quem "história e memória vivem às turras" —, defende que o tempo da peste é tão pavoroso que as pessoas preferem "esquecer de lembrar" (Sousa Gabriel, 2019). Para ela, em exemplo é que os relatos sobre a gripe espanhola de 1918 foram produzidos posteriormente. Os próprios cronistas brasileiros fizeram relatos tardios — alguns apenas em correspondências pessoais — , pois era como se não quisessem falar sobre aquilo. Esses relatos teriam sido "a memória sem memória do tempo da peste" (Sousa Gabriel, 2019).

Para Schwarcz e Starling (2020: 330), "diante do que parece inédito [o tempo presente de pandemia], nos dirigimos ao passado para chegar mais perto de indagações que precisam ser feitas hoje". Nessa retrospectiva, as pesquisadoras perceberam que as epidemias que acompanharam a trajetória humana encontraram a negação, mas também "provocaram reflexão, expressa sob a forma de memórias, crônicas, poemas, romances" (Schwarcz e Starling, 2020: 324). Na atual pandemia, novas formas de interação como WhatsApp, Facebook e Instagram trouxeram a reflexão para o tempo presente e articularam o debate em torno da construção da sua memória. Afinal,

Toda doença contagiosa é também um evento social. [...] 0 medo legítimo da peste leva a sociedade a enganar a si mesma para retardar o máximo possível o momento em que a doença terá de ser confrontada. [...] Quando a sociedade concorda em enxergar a enfermidade, significa que está ciente da situação amedrontada. É chegada a hora, então, de enfrentar aquilo que a atemoriza, evitando ou resistindo (Schwarcz e Starling, 2020: 46-47).

Ainda sobre a gripe espanhola, Schwarcz e Starling (2020: 327) observam que, para alguns analistas,

o momento estava mais para o elogio da modernidade e do progresso do que para a derrota coletiva impingida pela gripe. Além do mais, vivia-se um período em que a ciência médica, impulsionada pelas descobertas de diversas doenças e dos micro-organismos, também se associava a tal representação triunfante de modernidade.

Além do imaginário "triunfante de modernidade" que certamente contribuía para a negação da impotência da ciência, é bem verdade que o contexto comunicacional das primeiras décadas do século XX era bem distinto do que vivenciamos cem anos mais tarde. Ainda que a imprensa tenha noticiado a epidemia da gripe espanhola, cabe ressaltar que, especialmente no caso do Brasil, a população com acesso a jornais era bastante reduzida. 0 alcance 
das mídias impressas, naquele período, era muito menor do que veremos no desenrolar do século XX, com o advento das mídias eletrônicas de massa — rádio e televisão. Já não se pode dizer o mesmo em relação à pandemia da COVID-19. Sem considerar a participação da internet na difusão de dados sobre a doença, meios como rádio e televisão aberta abordam constantemente os impactos da enfermidade, suas consequências para a economia e a sociedade, fazendo com que o assunto seja obrigatoriamente pauta das conversas da população, determinando a agenda social e mobilizando a opinião pública, ação conhecida como agenda setting (Mccombs, 2004; Mccombs e Shawn, 1972). Apesar disso, e fomentada pela difusão das redes sociais, a negação da doença também existe agora. E - ao contrário do século passado — negando a ciência também.

Este papel da mídia de estabelecer a agenda da sociedade, determinando o que deve ou não ser considerado assunto relevante, sozinho não explica esta urgência de construção de memórias que identificamos na pandemia do coronavírus. A emergência da memória como um dos fenômenos da contemporaneidade, a nosso ver, constitui o pano de fundo para esta necessidade de produção de narrativas que nos permite não só lembrar, mas mesmo vivenciar esse tempo de enfermidade.

No primeiro momento, quando o isolamento social realmente se impôs, as pessoas sentiram necessidade de compartilhar seu cotidiano nas redes. Nessa situação, simples objetos que passavam despercebidos adquiriam mais importância, sendo ressignificados e ganhando novas funções. É esse o objetivo do projeto Objetos da Quarentena (2020), que será analisado neste artigo: examinar que memória é construída com base nessa exposição nas redes sociais de uma nova forma de encarar o dia a dia. Até porque, o mesmo poder que as redes têm de compartilhar sentimentos e construir memórias, têm também de torná-las efêmeras. E os objetos, sim, escrevem, inscrevem e ativam nossas memórias, enquanto narramos este tempo.

\section{O BOOM DA MEMÓRIA}

processo de valorização da memória vem sendo percebido há algumas décadas não só
nas reflexões acadêmicas, mas também corroborado pelo movimento de patrimonialização que se materializa com a multiplicação de museus, as filas para comprar ingressos para monumentos históricos e ainda a ampliação da lista de locais indicados a concorrer ao título de Patrimônio Mundial (Benhamou, 2016: 12). Todos, exemplos de "lugares de memória" de acordo com Nora (1993).

Andreas Huyssen (2000: 9) destaca que, a partir da década de 1980, o século XX, cujo início foi marcado pela modernidade e pela crença no futuro, assistiu à valorização da me- 
mória como "uma das preocupações culturais e políticas centrais das sociedades ocidentais", o que termina por instalar uma verdadeira cultura da memória. Candau (2009) chama essa tendência de mnetropismo, uma espécie de compulsão memorial. Esse movimento foi impulsionado, em grande parte, pelo esfacelamento das grandes narrativas, fundadas pela perspectiva do futuro e da utopia, e instaurou em seu lugar um olhar para o passado. "Quanto mais rápido somos empurrados para o futuro global que não nos inspira confiança, mais forte é o nosso desejo de ir mais devagar e mais nos voltamos para a memória em busca de conforto" (Huyssen, 2000: 32). 0 passado é familiar, reconhecível e diferente do presente. "Este apagamento de futuros possíveis instala, portanto, o desejo de buscar no passado parâmetros e, especialmente, um outro tempo que não o atual" (Santa Cruz, 2020: 100).

Foi considerando a "emergência da memória", surgida no fim do século XX - em oposição ao privilégio que se dava ao futuro, na primeira metade do mesmo século — que Huyssen (2000) conduz sua obra com o sugestivo título Seduzidos pela memória. Embora a obsessão pelo passado possa ser explicada "em função do fin de siècle", ele sugere ir mais fundo "para dar conta daquilo que se pode chamar agora de uma cultura da memória" — tão disseminada (Huyssen, 2000: 15).

É o medo do esquecimento que dispara o desejo de lembrar ou é, talvez, o contrário? É possível que o excesso de memória nessa cultura saturada de mídia crie uma tal sobrecarga que o próprio sistema de memórias fique em perigo constante de implosão, disparando, portanto, 0 medo do esquecimento? (Huyssen, 2000: 19).

0 interesse crescente pela memória contém pelo menos três facetas. Uma é que se traduz, por exemplo, em políticas de memória, dedicadas a impedir o esquecimento de determinados períodos históricos traumáticos ou autoritários, como o Holocausto ou ditaduras. "A nossa cultura secular, obcecada com a memória, está também de alguma maneira tomada por um medo, um terror mesmo, do esquecimento" (Huyssen, 2000: 19)

Outra é um interesse renovado por movimentos patrimonialistas e de restauração arquitetônica, além de tradições culturais locais, como sítios históricos e gastronomia. Ruth Adams (2013) discute a proeminência do "lobby da tradição" na Inglaterra, a partir dos anos 1970, e de como ele influencia a opinião pública em relação ao que pode ser considerado tradicional naquele país.

Uma terceira faceta é a apropriação pelo mercado deste desejo do passado, o que pode ser percebido pela onda de produtos nostálgicos, refilmagens, biografias, modas retrô, brechós, filmes históricos, entre outras mercadorias, em uma justaposição de passados que convivem em um presente expandido. 
Na visão de Huyssen (2000: 25), a resposta favorável ao que ele chama de mercados de memória é causada por uma "lenta, mas palpável transformação da temporalidade nas nossas vidas, provocada pela complexa interseção de mudança tecnológica, mídia de massa e novos padrões de consumo, trabalho e mobilidade global". Essas mudanças contínuas estabelecem novas percepções do tempo e do espaço, que sem dúvida acarretam impactos de toda ordem nas sociedades midiáticas contemporâneas (Huyssen, 2014: 16).

Essa temporalidade que vem se alterando estaria, portanto, na base de todo o esforço memorialístico da contemporaneidade, o que pode nos levar a concordar com Nora (1993), quando fala da necessidade dos lugares de memória - espaços físicos ou não de coleta e guarda do que deve ser lembrado - ante a aceleração do tempo. Segundo esse conceito, lugares de memória são espaços nos quais uma sociedade (seja nação, família, etnia, partido) consigna voluntariamente suas recordações ou então as considera como parte necessária de sua identidade.

Embora Huyssen (2000) considere que as velhas abordagens de memória coletiva não deem conta dos mecanismos de produção de memória (e de esquecimento) que vêm sendo gerados na contemporaneidade - até mesmo porque os grupos sociais estão cada vez mais fragmentados -, talvez, especificamente nestes tempos de pandemia, seja interessante voltar ao que Maurice Halbwachs (1968) propôs, em meados do século XX, ao considerar que a identidade coletiva precede a memória, e que esta é sim social, à medida que é construída nas relações sociais. Nesse sentido, as lembranças que estamos construindo neste momento não seriam coletivas? Não estamos sendo constantemente lembrados — pelos outros e pelas vivências dos outros — da nossa própria experiência e daquilo em que "somente nós" estamos envolvidos?

Entre os elementos relevantes para esse processo, desponta o testemunho - a narrativa em primeira pessoa de alguém que conta sua vida, sua experiência, "para conservar a lembrança ou para reparar uma identidade machucada" (Sarlo, 2007: 19).

\section{TESTEMUNHO}

O século XX foi chamado de era da testemunha (Didi-Huberman, 2012: 52), em uma referência à valorização do relato dos sobreviventes das guerras e dos genocídios do período, os quais passaram a ser ouvidos principalmente por meio da literatura a partir dos anos 1950.

0 reconhecimento do testemunho como um aspecto relevante na reconstituição do passado está aliado à fragmentação do discurso histórico. Essa condição levou a história 
social e cultural a deslocar seu estudo para as margens da sociedade moderna, modificando a noção de sujeito e a hierarquia dos fatos, destacando os pormenores cotidianos articulados em uma poética do detalhe e do concreto, como destaca Sarlo (2007: 43). 0 testemunho assume, assim, um novo lugar, reconhecido como registro da vivência, ainda que com uma subjetividade inerente ao processo. Na raiz do testemunho, está a capacidade de relatar um acontecimento e partilhá-lo com uma audiência.

[...] o testemunho carrega uma faceta relacional. Ele não existe sem diálogo; só existe diante dos outros e para os outros. Não há testemunha para si, nem sozinha. Ela é, inevitavelmente, intersubjetiva. Mas a testemunha atesta e traz em si mais do que si mesma. É portadora de uma verdade — forjada na experiência — que, por isso mesmo, não pode ser reduzida a uma mera opinião. E, portanto, é também performativa. Ou seja, um sujeito que fala como um sujeito que age (Bruck; Vargas; Moreira, 2020: 15).

0 testemunho, portanto, adviria do agir e da vivência, algo que aconteceu no passado de quem está apresentando aquela história. "0 narrador retira da experiência o que ele conta: sua própria experiência ou a relatada pelos outros" (Benjamin, 1982: 201). Sarlo avança no entendimento de uma relação direta de dependência entre a experiência e o seu relato.

A narração da experiência está unida ao corpo e à voz, a uma presença real do sujeito na cena do passado. Não há testemunho sem experiência, mas tampouco há experiência sem narração: a linguagem liberta o aspecto mudo da experiência, redime-a de seu imediatismo ou de seu esquecimento e a transforma no comunicável, isto é, no comum. A narração inscreve a experiência numa temporalidade que não é a do seu acontecer [...], mas a de sua lembrança (Sarlo, 2007: 25).

Se, portanto, o testemunho não é o relato do momento - classificação que caberia com mais propriedade ao jornalismo — , mas se inscreve na revisitação do passado, em que medida relatos de acontecimentos que ainda estão em pleno curso, como é o caso da pandemia do coronavírus, poderiam ser testemunhos memoriais? Em outras palavras, estamos lembrando o que ainda estamos vivendo?

\section{REGISTROS DA PANDEMIA}

Eoram muitas as iniciativas que promoveram tanto reflexões sobre quanto registros e me1 mórias dos tempos da pandemia da COVID-19. Como mencionado, o volume desta produção deve-se muito ao fato do uso intenso das tecnologias de comunicação. Diferentemente do momento da grande pandemia da gripe espanhola, agora o mundo está mais globalizado e mais conectado. Por isso, o vírus alastrou-se pelo mundo de forma mais rápida, e em maiores proporções. Nós tomamos conhecimento dos fatos em tempo real. Também somos mais 
urbanos e convivemos - ou, pelo menos, convivíamos até o início da atual pandemia — com mais pessoas em nossos ambientes sociais e de trabalho, consequentemente temos mais dificuldade de nos mantermos em isolamento. Em contrapartida, temos à disposição tecnologias que nos permitem a conexão com os nossos círculos de trabalho e convívio social a distância.

As iniciativas que envolveram temas relacionados à pandemia algumas vezes foram individuais, outras coletivas. Algumas vezes pessoais, outras institucionais. Algumas vezes acadêmicas, outras com propósitos mais específicos. Algumas valorizam imagens, outras narrativas e ainda outras a cultura material. De alguma forma, todas acessam a vivência do período de pandemia e/ou de isolamento, assim podendo funcionar como futuras âncoras de memória — algumas, inclusive, têm o intuito de ser preservadas para que sirvam de reflexões posteriores. Mas algumas vão se perder — ou já se perderam — na grande nuvem de dados e informações que paira sobre nossos meios de comunicação. Muitas vozes. Pluralidades. Sem pretender fazer um arrolamento completo ou exaustivo, mas procurando mostrar a diversidade de aspectos levantados, assim como a importância dada às diferentes implicações da pandemia — econômicas, sociais, culturais e subjetivas impostas à sociedade — - citamos algumas iniciativas e seus produtos.

A produção bibliográfica foi rápida e diversificada. Um dos últimos livros a ser lançado no Brasil sobre o tema, em 2020, foi Quarenta e quatro em quarentena: conversas com Miguel Pinto Guimarães, em que o autor - um arquiteto conhecido por gostar de aglomerações e de agregar pessoas de diversos meios - reuniu as conversas que promoveu em lives abertas ao grande público, com artistas, arquitetos, políticos e outras figuras conhecidas (Guimarães, 2020).

Também arquitetas e urbanistas são Andrea Borges e Leila Marques, organizadoras de Coronavírus e as cidades no Brasil: reflexões durante a pandemia, que reúne profissionais acadêmicos entre arquitetos, urbanistas, economistas, historiadores, cientistas sociais, engenheiros e filósofos envolvidos com o planejamento urbano, que expõem suas reflexões sobre as implicações da pandemia na vida nas cidades. Aspectos que vão desde as entregas de delivery, o uso das áreas comuns dos condomínios, o convívio de muitas pessoas em espaços de moradia exíguos, o trabalho informal, o transporte urbano, a população de rua e os caminhos a serem trilhados pós-pandemia (Marques e Borges, 2020).

Os ensaios de No tremor do mundo: ensaios e entrevistas à luz da pandemia, organizado por Luisa Duarte e Victor Gorgulho, tratam da grande repercussão da pandemia, por meio de vozes oriundas de diversos campos, justamente com o objetivo de construir memórias deste momento tão singular da história, com esperança de que a elaboração do presente possa contribuir com a irrigação da imaginação do futuro (Duarte e Gorgulho, 2020).

Pandemia e agronegócio: doenças infecciosas, capitalismo e ciência, do biólogo estadunidense Rob Wallace, defende que novos vírus, que há alguns anos amedrontam o planeta, são 
resultado da maneira como o homem passou a criar animais para consumo nos últimos quarenta anos. 0 autor, que vem alertando para isso, menciona as origens da SARS, da gripe aviária e da gripe suína, prevenindo que, se não modificarmos a maneira como criamos animais para abate, vamos lidar, em curto prazo, com novas formas de vírus cada vez mais mortais (Wallace, 2020).

Em A pandemia e o pandemônio: ensaio sobre a crise da democracia brasileira, André Duarte analisa a crise democrática no Brasil, acirrada pela pandemia, que expõe as contradições inerentes às nossas experiências comunitárias e o surgimento de uma necropolítica que escancara o mal radical de nosso corpo social, transformando a gestão da vida em produção da morte (Duarte A. M., 2020).

Citamos ainda a obra do filósofo Pedro Duarte — A pandemia e o exílio do mundo que reuniu textos escritos por ele no calor da emoção e da perplexidade ante a pandemia, entre abril e maio de 2020. Como se quisesse se desculpar das críticas frequentemente dirigidas à filosofia por se manter distante do mundo concreto, o autor promove um diálogo entre seu repertório teórico e referências comuns da vida.

E penso na quantidade enorme de textos, como este aqui, que desde o começo do ano são escritos sobre a pandemia. Por um lado, é claro, o tema se impõe e convoca compreensão para nos aproximarmos dele. Por outro, acredito que há uma vontade de escrever sobre ele no sentido do poema da Bishop: um misto de testemunho e aviso, de lembrança e recomendação (Duarte P., 2020: 77-78).

No campo acadêmico, ainda no primeiro semestre, o Grupo de Pesquisa Espaço, Corpo, Arte e Estética (GECAE) do Programa de Pós-Graduação em Comunicação Social da Universidade de Brasília abriu chamada de artigos para o e-book Cartografias do Isolamento, que buscava reunir reflexões sobre a questão corpo-cidade e as relações afetivas com a cidade com o objetivo de aproximar o diálogo entre a universidade e a comunidade em período tão sensível. A publicação foi um desdobramento do projeto Cartografias subjetivas do isolamento: repensando os afetos, os deslocamentos e cidade em tempos de pandemia, que pretendia "a elaboração de um mapa não de um território, atrelado aos aspectos físicos de uma determinada região, mas, principalmente, ao desenho de relações, jogos de poder, discursos, movimentos, afetos, modos de subjetivação e resistência, dentre outros" (Repositório Covid-19, 2020) pela coleta de depoimentos e pesquisas netnográficas em mídias sociais. Diversos produtos, como vídeo, textos, debates e webnários, deveriam mostrar as reconfigurações dessa cartografia das subjetividades, especialmente em Brasília, mas também em outras cidades.

Alguns fazeres artísticos que dependiam de reunião de pessoas tiveram que se reinventar. As performances teatrais e musicais passaram a ser exercidas a distância. Em um primeiro 
momento, sem cobrar ingresso, em troca de promover bem-estar e/ou de fazer campanha para causas sociais. Destacando-se a importância do fazer colaborativo nas áreas criativas, cita-se o projeto Histórias do Confinamento, do Grupo Galpão — um espetáculo teatral lançado em novembro de 2020, criado com base na seleção de 500 relatos sobre a quarentena enviados pelo público, a partir de maio do mesmo ano, cuja transmissão, ao vivo, deu-se pelo canal do YouTube do grupo (Grupo Galpão, 2020).

Fotógrafos também se reinventaram. 0 jornal Correio Braziliense publicou uma matéria sobre a fotografia remota: "Antes dos cliques, os fotógrafos fazem um tour [virtual] na casa dos modelos para buscar cenários e locais para colocar o celular, além de avaliar a iluminação" (Izel, 2020). Na reportagem, são mencionados vários fotógrafos. Entre eles, Jorge Bispo disse que, mais do que nunca, foi importante entender que "durante meses nosso mundo imagético vai se resumir às nossas casas e os registros não serão em full HD" (Izel, 2020). Tainá Frota percebeu que, mesmo em isolamento, as pessoas queriam registar momentos especiais que não podiam esperar - como uma gravidez. Para ela, "o principal é ser uma lembrança para as pessoas, de quando elas estavam passando por isso juntas. Esse é o grande valor da fotografia" (Izel, 2020). E Sérgio Zalis dedicou-se durante um mês a "viajar (remotamente) pelo mundo" para clicar amigos, buscando mostrar um pouco de como estava sendo a experiência de cada um. As imagens foram postadas no seu perfil de Instagram seguidas de um texto, que, para ele, foi fundamental, já que o que se propunha a fazer era contar essas histórias.

Centros de diversas áreas do conhecimento acadêmico, em várias partes do mundo, trabalharam para o desenvolvimento de projetos que pudessem colaborar com as dificuldades que a população do mundo todo atravessava. As propostas vindas pelo terreno do design foram compiladas pelos alunos do MA History of Design do Royal College of Art de Londres que criaram uma plataforma interativa para postagem de arquivos.

"Escrevendo, retemos aquilo que está se passando e advertimos sobre o que ainda está por vir" (Duarte P., 2020: 78), por isso, entre as inúmeras iniciativas colaborativas que poderiam ser mencionadas, destacam-se os projetos Inumeráveis e Testemunhos do Isolamento. 0 primeiro é um memorial virtual dedicado à história de cada uma das vítimas do coronavírus no Brasil, "uma obra do artista Edson Pavoni em colaboração com Rogério Oliveira, Rogério Zé, Alana Rizzo, Guilherme Bullejos, Gabriela Veiga, Giovana Madalosso, Rayane Urani, Jonathan Querubina e os jornalistas e voluntários que continuamente adicionam histórias à este memorial" (Inumeráveis, 2020). Em apoio a essa iniciativa, o jornal O Globo, em 10 de maio de 2020, publicou o nome e uma pequena história de cada um dos 10 mil brasileiros cujas mortes haviam sido confirmadas à época como decorrência do coronavírus. 
Testemunhos do Isolamento é um projeto promovido pelo Arquivo Geral da Cidade do Rio de Janeiro (AGCRJ), postado na primeira página do site da instituição. Considerando que, embora as experiências de pandemia, quarentena e isolamento social sejam coletivas, elas afetam de forma singular cada pessoa, 0 arquivo da cidade propôs-se a coletar e documentar, a partir de maio de 2020, histórias e testemunhos do período pela ótica dos indivíduos e do seu cotidiano. Considerando a importância do momento histórico, a proposta da instituição foi salvaguardar esses depoimentos e garantir acesso à essa documentação para pesquisadores que se interessem por estudar esse período. 0 projeto respeita a vontade do depoente pelo seu anonimato ou pela sua não autorização na revelação de seu material. 0 processo de coleta é todo on-line, por meio de um formulário que apresenta questões do tipo: "Como o isolamento social alterou seus encontros com seus amigos?"; "Como foi para você saber sobre os primeiros casos na sua cidade?". Além disso, o sistema permite que o depoente compartilhe arquivos de "arte, poesia, fotografias, pinturas, vídeos" ou ainda comente algo que não tenha sido abordado pelas perguntas (Arquivo Geral da Cidade do Rio de Janeiro, 2020).

Sobre esse projeto, o AGCRJ se disse inspirado por iniciativas internacionais semelhantes, como as da Associação Pública dos Historiadores de Nova York e do Arquivo Municipal de Barcelona. Também foi um projeto da universidade estadunidense Parsons, de Nova York, o Atlas of Everyday Objects - que inspirou o Laboratório de Estudos de Memória Brasileira e Representação (Lembrar), do Mestrado Profissional em Gestão da Economia Criativa (MPGEC), da ESPM-Rio, no qual as autoras atuam, a desenvolver o Projeto Objetos da Quarentena (2020), que será detalhado na próxima seção.

\section{A MATERIALIDADE DO COTIDIANO}

proposta do Projeto Objetos da Quarentena (2020) é coletar, por meio de convites de
postagens nas redes sociais, objetos que representem o momento da quarentena da COVID-19 para diversas pessoas. Usuários dessas plataformas foram estimulados a postar fotos e textos de objetos que tenham sido redefinidos, redimensionados, redescobertos ou adquiriram novos usos em sua vida pelo isolamento imposto pela pandemia. Pedia-se que as pessoas acrescentassem, em suas postagens, a hashtag \#objetosdaquarentena, de modo a permitir, na sequência, a recuperação dessas imagens e textos. A postagem, portanto, era livre, sem estar restrita a nenhum padrão ou direcionamento. As contribuições chegaram nos primeiros meses da pandemia. 
0 resultado recolhido pode parecer, à primeira vista, uma "mera galeria de fotos", mas a proposta é aprofundar a discussão sobre o lugar dos objetos intermediando relações humanas, contribuindo para a análise deste momento.

0 antropólogo Arjun Appadurai defende a tese de que as mercadorias (objetos de valor econômico), tal como as pessoas, têm uma vida social própria. 0 autor cita o sociólogo George Simmel (1858-1918) para explicar que valor não é "uma propriedade inerente aos objetos, mas um julgamento que sujeitos fazem sobre eles" (Appadurai, 2008: 15). Assim os bens são portadores de significados que não são intrínsecos a eles, mas sim às redes de relações sociais e culturais as quais estão conectados. Com base na questão proposta por Appadurai (2008: 19) de que "poucos negariam que a mercadoria é algo completamente socializado, mas que seria necessário responder em que consiste esta sociabilidade", vale agora perguntar em que consiste a sociabilidade (as relações sociais) em tempos em que 0 distanciamento físico é imposto aos grupos sociais.

Manovich (2015) aponta que vivemos a cultura do arquivo, visto que a cultura digital ampliou o espaço dos objetos que não contam histórias; itens individualizados em que a importância é próxima entre eles. Ele alerta que a nossa apreensão do mundo é maior pelo banco de dados do que pelas narrativas e explica que é grande o consumo de micronarrativas porque, como elas são pessoais, não provocam incômodos. Ele atribui a isso a quantidade de relatos em primeira pessoa em comparação com poucos em terceira.

Objetos da Quarentena (2020) é também um projeto de construção de memória, posto que, daqui a algum tempo, os registros dos artefatos ali postados ajudarão a acessar as lembranças do período.

No campo da memória, Chagas destaca que os objetos são suporte de memória e têm vida social intensa. "Nossos suportes de memória não estão somente nos textos, eles não estão apenas na narrativa oral, ainda que tudo isso seja importante; os nossos suportes de memória também passam pelos objetos materiais" (Chagas, 2004: 56-57).

Um objeto sempre remete a um lugar, um momento ou alguém.

É nesse sentido que é possível falar numa memória que impregna e restitui "a alma nas coisas", referida a uma paisagem (inter)subjetiva onde o objeto (re)situa o sujeito no mundo vivido mediante o trabalho da memória, ou ainda, é da força e dinâmica da memória coletiva que 0 objeto, enquanto expressão da materialidade da cultura de um grupo social, remete à elasticidade da memória como forma de fortalecer os vínculos com o lugar, considerando as tensões próprias do esquecimento (Silveira e Lima Filho, 2005: 39).

Objetos da Quarentena (2020) é um projeto em desenvolvimento, ainda em fase de análise, que procura entender o papel do objeto na identidade, bem-estar ou autoestima do 
indivíduo e o que está prevalecendo na relação das pessoas com os objetos no período de isolamento social. Praticidade e funcionalidade doméstica e profissional? Lazer e divertimento em casa? Novas possibilidades de interação social? Emoção, evasão, memória e nostalgia? Essas são algumas chaves de análise para a futura categorização da coletânea de objetos.

A materialidade do entorno humano está associada a uma série de processos que envolvem aspectos sociais, culturais, tecnológicos e econômicos onde, por vezes, sobressai 0 valor funcional do objeto, por outras, seu valor simbólico.

A interação do homem com a sua própria materialidade, a qual envolve a sua existência, ressalta a importância dos estudos acerca da cultura material, que, entre dimensões, abordagens e domínios, mostra-se apta a examinar o objeto material, não somente tomado em si mesmo, mas sim em seus usos, nas suas apropriações sociais, a partir das técnicas de produção envolvidas; na sua importância econômica e suas necessidades sociais e culturais (Dohmann, 2017: 42).

Para o teórico cultural Baudrillard (1989), os objetos adquirem, simbolicamente, vida própria, transcendendo aquilo que os designers modernos — advindos das escolas racionalistas defendiam: a funcionalidade. Os objetos são mediadores de relações humanas. Assim, para ele, o próprio significado do adjetivo "funcional" pode ser visto de forma mais abrangente, não se restringindo à praticidade dos objetos em relação a tarefas, mas também à sua capacidade de interagir e de significar. Em face à valorização da funcionalidade, para ele, o homem é "reduzido à incoerência", em face ao objeto funcional, "torna-se disfuncional" (Baudrillard, 1989: 63).

Com efeito, a dinâmica concreta do esforço que se abstraiu nos mecanismos e nos gestos de controle nem por isso desapareceu: "interiorizou-se em uma dinâmica mental, a do mito funcionalista. A da virtualidade de um mundo totalmente funcional, de que cada objeto é já o indício. 0 gestual reprimido torna-se mito, projeção, transcendência" (Baudrillard, 1989: 63).

Naquilo que chamou de "sistema não funcional [de objetos]" e seus discursos subjetivos, Baudrillard lembra dos objetos antigos (singulares ou exóticos) que "parecem contradizer as exigências do cálculo funcional para responder a um propósito de outra ordem: testemunho, lembrança, nostalgia, evasão" (Baudrillard, 1989: 63). Assim, o objeto antigo pode ser uma escolha estética ou um distintivo de exclusividade. Pode trazer consigo a memória de uma experiência de vida ou a nostalgia de algo que se imagina melhor do que o aqui e agora.

Nostalgia é um neologismo inventado no século XVII por um médico suíço para designar uma doença que afetava soldados e trabalhadores afastados de sua terra natal (Boym, 2001). Dois séculos mais tarde, o conceito perdeu seu significado médico, deixando de ser um lamento por uma casa perdida para se transformar em um lamento pelo passado (Landwehr, 2018), isto é, de um deslocamento espacial para um deslocamento temporal (Keightley e 
Pickering, 2006). A conotação, porém, era negativa, como uma oposição à modernidade e ao progresso, uma fuga da realidade. Somente no fim do século XX é que a nostalgia foi reabilitada como um fenômeno psicológico e sociológico. Keightley e Pickering (2006: 938) consideram que ela pode ser tanto melancólica quanto utópica, uma ferramenta crítica, que aciona usos ativos e produtivos do passado, mas que também pode se traduzir de modo estéril, impotente e não relacional.

Sedikides et al. (2015) mostraram que nostalgia pode funcionar como recurso afetivo, auxiliando as pessoas a lidarem com situações difíceis, como um recurso psicológico adaptativo. "A nostalgia pode se tornar uma força ativa que motiva as pessoas para a lembrança ativa" (Kalinina, 2016: 7, tradução nossa)1. Bonnett (2016) sublinha que a nostalgia é um sentimento universal, não é uma manifestação relacionada ao Ocidente. Niemeyer (2014: 10, tradução nossa) $)^{2}$ aponta que nostalgizar é "um ato de fala que pode potencialmente se transformar em um processo criativo pragmático".

Se considerarmos nostalgia como um sentimento produtivo e com potencial de dimensão ativa, vamos encontrá-la em muitas das postagens feitas com a \#objetosdaquarentena, como a de Martha Luiza Quintella Brasil (Figura 1): "Essa poltrona. Ela me acompanha há muito tempo, era importante na época em que amamentava minhas filhas. Depois, caiu no esquecimento. Durante a quarentena ela aparece como um refúgio confortável para leitura e outras atividades".

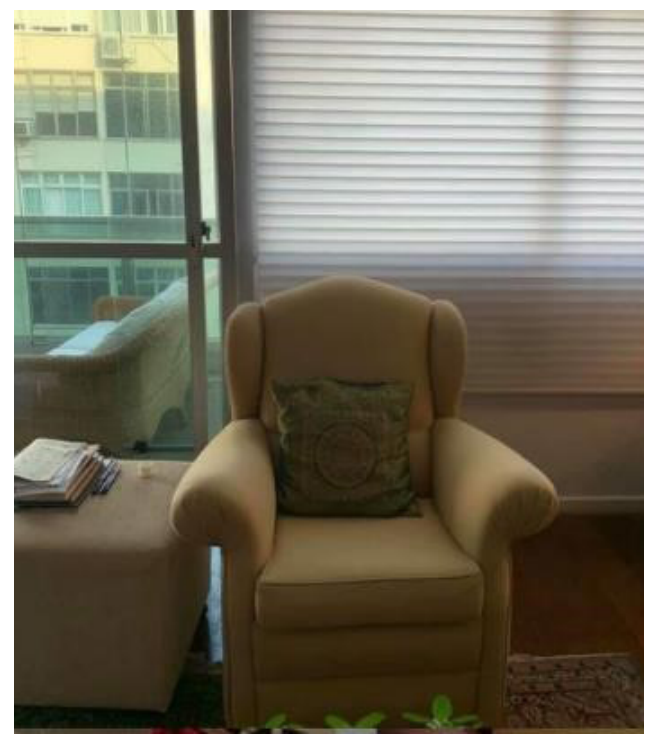

Figura 1 - Poltrona.

Fonte: perfil de Martha Luiza Quintella Brasil no Instagram (2020). Disponivel em: <https://www.facebook.com/ photo.php?fbid=10222394499790752\&set=p.10222394499790752\&type=3>. Acesso em 10 maio 2020 . 
Ou a de Adelaide Chao, que recoloca em uso um objeto que passa a dar novo colorido ao cotidiano pandêmico (Figura 2): "Eu nem lembrava que ela existia. Comprei em uma viagem a Aracaju. Foi ótimo tirá-la do armário e usar com frequência. Ler, falar ao celular, ficar na varanda respirando. Uma rede tem seus encantos".

A quarentena, de modo geral, tem sido um tempo de espera e expectativa, e os objetos fazem parte desse processo. A postagem de @robalessandro exemplifica isso (Figura 3): "Jacira me acompanha há alguns anos insistente, ela se apega à certeza de que terá outra função após ter cumprido a sua primeira eu me apego também, certo de que ela cumprirá outra talvez por isso não dei meu adeus já ensaiei outros porquês para ela mas não encontrei ainda o que faça jus a seu valor certo de que iremos encontrar, eu e ela, esperamos".

Para o engenheiro e psicólogo Donald Norman, é a categoria "interação social" que garante o sucesso de um produto. Assim, muito mais que um instrumento de comunicação, o celular já era avaliado por ele, em 2004, como uma ferramenta emocional e um facilitador social. "É claro que a utilidade e usabilidade são importantes, mas sem diversão e prazer, alegria e entusiasmo, e até ansiedade e raiva, medo e fúria, nossas vidas seriam incompletas" (Norman, 2008: 28). Essa perspectiva aflora na foto de um teclado de computador (Figura 4):

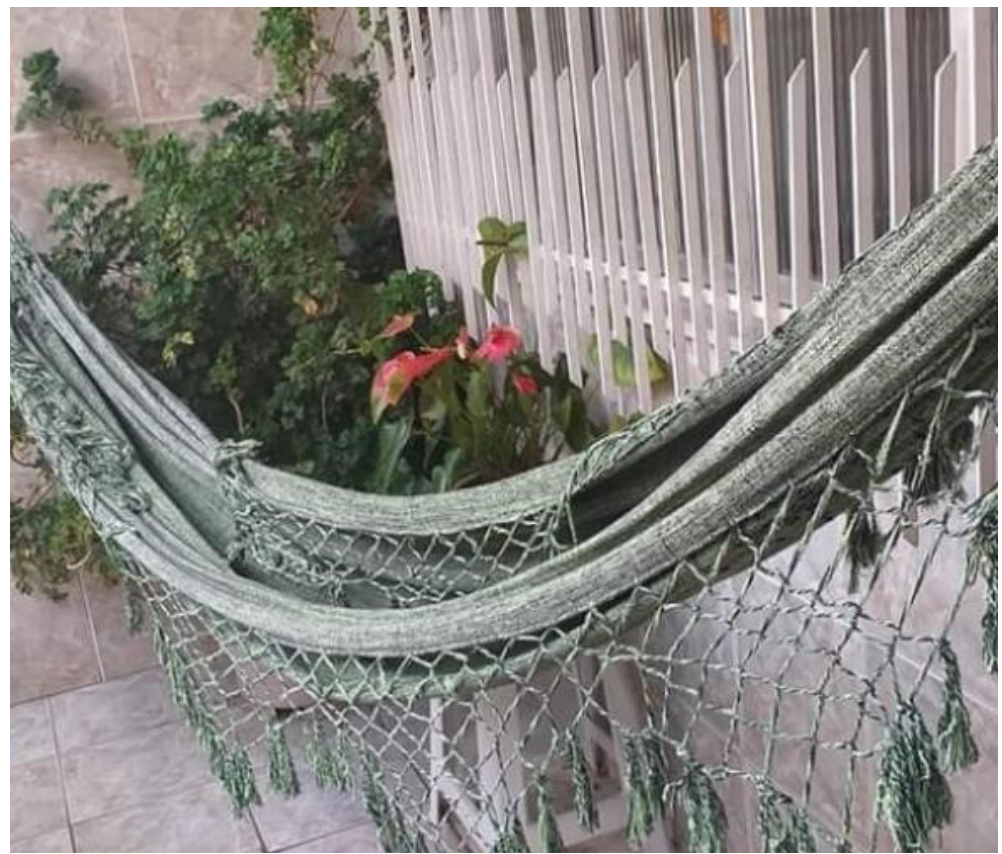

Figura 2 - Rede.

Fonte: perfil de Adelaide Chao no Facebook (2020). Disponivel em: <https://www.instagram.com/p/CBDe1PmghF-/>. Acesso em: 05 jun. 2020. 


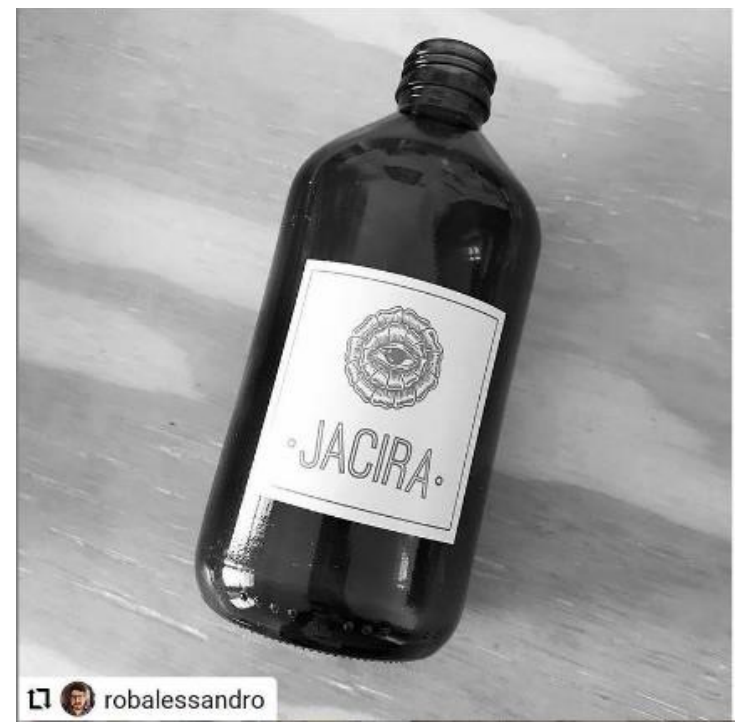

Figura 3 - Vidro de Jacira.

Fonte: perfil de Robson Alessandro no Instagram (2020). Disponivel em: <https://www.instagram.com/p/CCexxlEnCie/>. Acesso em: 12 jul. 2020

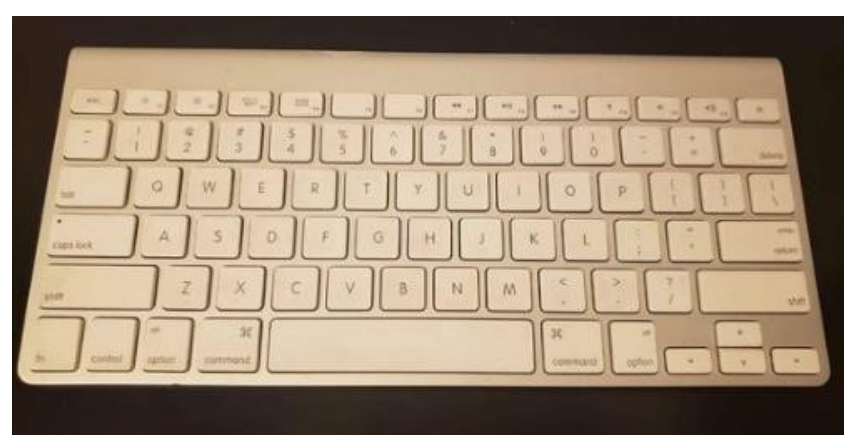

Figura 4 - Teclado de computador.

Fonte: perfil de Barbara Yehudit Ferrante no Facebook (2020). Disponivel em: < ttps://www.instagram.com/p/CBDewlHAOza/>. Acesso em: 05 jun. 2020.

"É a forma de estar informada, conectada, e manter a produtividade. Já me peguei pensando várias vezes se isso tivesse ocorrido nos anos 80 , onde no máximo tínhamos um telefone fixo" (Barbara Yehudit Ferrante).

Outro exemplo dado por Norman é em relação a sua coleção de bules de chá. Dependendo do seu convidado, ele escolhe o apetrecho pelo seu charme, estilo ou engenhosidade. "O design é importante para mim, mas a minha escolha depende da ocasião, do contexto e, sobretudo do meu humor", e destaca que cada um dos bules tem um significado e uma história próprios (Norman, 2008: 24). 
Ressignificação dos objetos também aparece nos relatos e nas imagens do projeto, como na postagem de Jaqueline Resch: "Na pandemia virou peso para exercitar os braços na aula de pilates!!" (Figura 5).

Donald Norman, que trabalha como consultor de desenvolvimento de produtos para várias empresas, destaca que afeto e emoção são questões principais na relação das pessoas com os objetos, mas também "cruciais para a tomada de decisão no dia-a-dia" (Normam, 2008: 30, 32). E mais: que a emoção torna as pessoas mais inteligentes e afeta a maneira como se comportam, sentem e pensam.

Nos registros colhidos pelo projeto \#objetosdaquarentena, encontramos uma avó que postou a foto do que daria aos netos e não pôde por conta da pandemia: "Ovos de Páscoa que esperam o encontro com os netos" (Angela Girardi). Na sua escolha por eleger os doces como seus objetos da quarentena, ela aciona emoção, afeto, mas também evidencia a racionalidade da decisão de esperar o momento adequado para entregar o presente (Figura 6).

0 projeto também identificou postagens que fazem alusão direta à capacidade dos objetos de reterem a memória deste período ou de ajudarem a escrevê-la (Figura 7): "Vidros de conserva transformados em 'jardim de janela'. Com os rótulos para lembrar de cada comida do cardápio no período" (Sandra Sanches).

E outros relatos que sinalizam a habilidade dos objetos de se transformarem em rastros de si mesmos, deixando marcas nas nossas vidas e levantando a indagação sobre o que

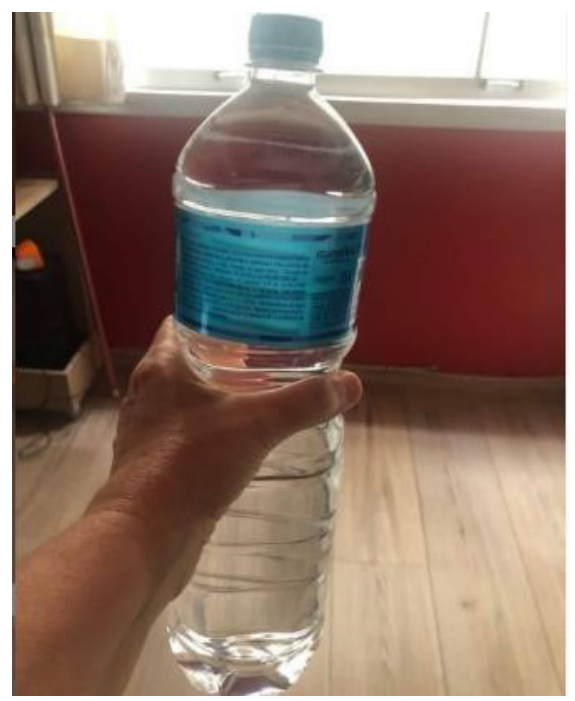

Figura 5 - Peso de água.

Fonte: perfil de Jaqueline Resch no Facebook (2020). Disponível em: <https://www.instagram.com/p/CBDdSU2gES3/>. Acesso em: 05 jun. 2020. 


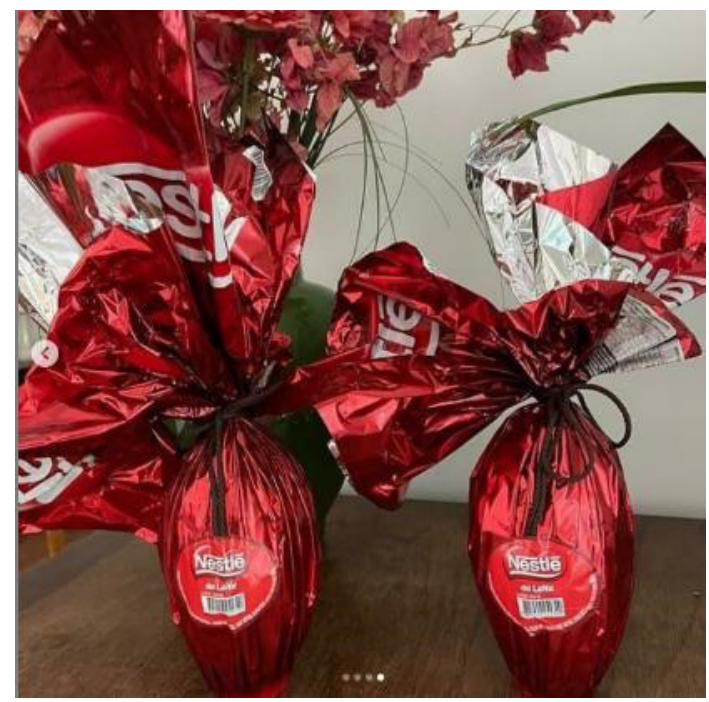

Figura 6 - Ovos de Páscoa.

Fonte: arquivo pessoal de Angela Girardi (2020).

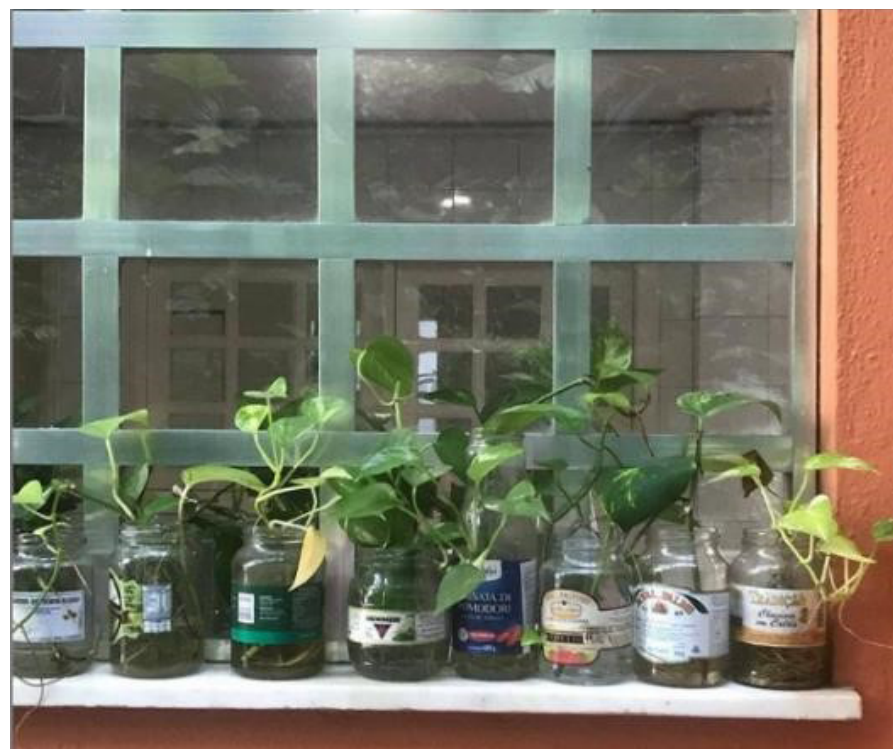

Figura 7 - Temperos.

Fonte: perfil de Sandra Sanches no Instagram (2020). Disponível em: https://www.instagram.com/p/CA6ACQ0AJVB/>. Acesso em: 01 jun. 2020.

lembraremos deste momento (Figura 8): "Queimei o dorso da mão. A dor que sinto não se acalma com aloe vera recém colhida. Vai deixar uma cicatriz, depois que sumir a auréola. Sempre olharei para ela e lembrarei da panela" (Patrícia Brasil). 


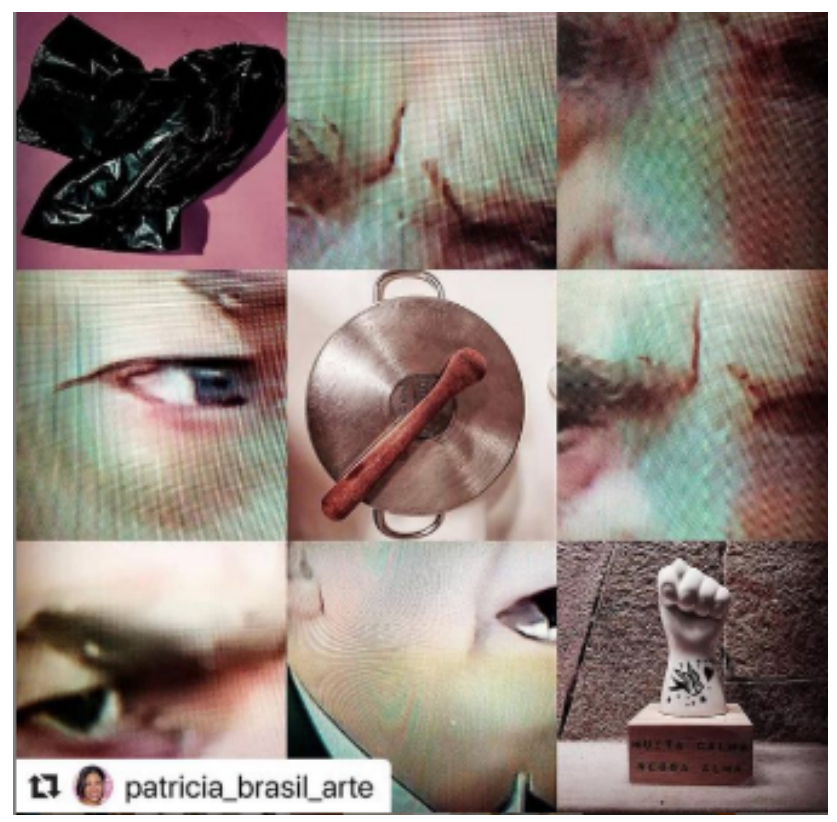

Figura 8 - Queimadura.

Fonte: perfil de Patrícia Brasil no Instagram (2020). Disponível em: <https://www.facebook.com/photo?fbi$d=3358864157457026 \&$ set=a.262260353784104 $>$. Acesso em 05 jun. 2020

Os exemplos aqui listados indicam que, em função da pandemia, ao identificarmos objetos que se tornaram relevantes, indispensáveis, com novos usos, estamos não apenas registrando no que se transformou o nosso cotidiano pelo isolamento social. Estamos falando da nossa relação com os objetos e de como eles escrevem e inscrevem as nossas memórias.

\section{NOTAS FINAIS}

$E^{s}$ ste artigo pretendeu tratar da urgência de construção de memória desencadeada pela pandemia da COVID-19. Para isso, iniciamos comparando o atual momento com um evento semelhante, o da gripe espanhola, mas deixando clara a diferença de tratamento entre as duas pandemias. Enquanto na gripe espanhola, do início do século XX, as pessoas preferiram "esquecer de lembrar" , na situação desencadeada pelo coronavírus no fim de 2019 e durante 0 ano de 2020, assistimos a uma proliferação de projetos e iniciativas de registro memorial desses tempos.

A construção de memórias sobre a pandemia, enquanto ela ainda acontece, soa também como um sinal de uma nova temporalidade. "De toda maneira, onde existe silêncio, sobram contradição e incompreensão" (Schwarcz e Starling, 2020: 328). Se, no caso da gripe espanhola, os primeiros relatos não jornalísticos só apareceram algum tempo depois, quando 
se tornou possível processar e analisar o que havia acontecido com a sociedade, na atual situação, a geração de conteúdo sobre o tempo da enfermidade tornou-se uma estratégia para sobreviver a este momento, enquanto ele é registrado.

Para compreender esse fenômeno, o artigo referenciou o movimento de valorização da memória e do testemunho nas sociedades ocidentais contemporâneas e apresentou o projeto colaborativo Objetos da Quarentena (2020), cuja proposta é aprofundar a discussão sobre o papel dos objetos na intermediação das relações humanas e construção da memória em tempos de isolamento social.

Na análise de algumas imagens publicadas com a hashtag \#objetosdaquarentena, percebe-se o quanto os objetos que nos cercam, e dos quais fazemos uso muitas vezes mecanicamente, compõem nosso dia a dia e ajudam a relatar nossas vivências.

Esses objetos, cujo valor é social e culturalmente estabelecido e negociado, colaboram para que possamos falar sobre este período, mesmo quando nos faltam palavras. Eles se expressam por nós. Os objetos escrevem e inscrevem nossas memórias, enquanto narramos este tempo de confinamento, de espera e expectativa.

Conflitos de interesse: nada a declarar.

Fonte de financiamento: nenhuma.

Contribuições dos autores: Perrotta I.; Santa-Cruz, L.: Administração do Projeto, Curadoria de Dados, Redação, Revisão e Edição.

\section{NOTAS}

1 No original: "Nostalgia can become an active force that motivates people towards active remembering".

2 No original: "[... an act of speech that can potentially turn into a pragmatic creative process".

\section{REFERÊNCIAS BIBLIOGRÁFICAS}

ADAMS, R. The V\&A, the destruction of the country house and the creation of "English heritage". Museum and Society, v. 11, n. 1, p. 1-18, mar. 2013.

APPADURAl, Arjun. A vida social das coisas: as mercadorias sob uma perspectiva cultural. Niterói: EdUFF, 2008. ARQUIVO GERAL DA CIDADE DO RIO DE JANEIRO. Testemunhos do isolamento. Disponível em: <https:// www.rio.rj.gov.br/web/arquivogeral/testemunhos-do-isolamento>. Acesso em 10 dez. 2020. 
BAUDRILLARD, J. O sistema dos objetos. São Paulo: Perspectiva, 1989.

BENHAMOU, F. Economia do patrimônio cultural. São Paulo: Edições Sesc, 2016.

BENJAMIN, W. Obras escolhidas: magia e técnica, arte e política. São Paulo: Brasiliense, 1982.

BONNETT, A. The geography of nostalgia: global and local perspectives on modernity and loss. London: Routledge, 2016.

BOYM, S. The future of nostalgia. New York: Basic Books, 2001.

BRUCK, M. S.; VARGAS, H.; MOREIRA, J. Memória, poder e verdades: disputas de sentidos no acionamento do memorável no caso do Fundão. In: ENCONTRO ANUAL DA COMPÓS, 29., 2020, Campo Grande. Anais [...]. Campo Grande: Universidade Federal de Mato Grosso do Sul, 23 a 25 de junho de 2020. Disponível em: <https://www.compos.org.br/menu_anais.php?idEncontro=MzA=>. Acesso em 15 dez. 2020.

CANDAU, J. Bases antropológicas e expressões mundanas da busca patrimonial: memória, tradição e identidade. Revista Memória em Rede, Pelotas, v.1, n.1, dez.-mar. 2009. Disponível em: <https://www.ufpel. edu.br/ich/memoriaemrede/site/revista/edicao-01/>. Acesso em: 15 nov. 2020.

CHAGAS, M. S. Os museus e as novas formas de institucionalização das memórias: tecnologias e práticas social. Comunicações do ISER, Rio de Janeiro, v. 59, p. 55-60, 2004.

DIDI-HUBERMAN, G. Imagens apesar de tudo. Lisboa: KKYM, 2012.

DOHMANN, M. Cultura material: sobre uma vivência entre tangibilidades e simbolismos. In Diálogo com a Economia Criativa, Rio de Janeiro, v. 2, n. 6, set./dez. 2017. https://dx.doi.org/10.22398/25252828.2641-53

DUARTE, A. M. A pandemia e o pandemônio: ensaio sobre a crise da democracia brasileira. Disponível em: $\quad<$ https://www.viaverita.com.br/product-page/a-pandemia-e-o-pandemônio-ensaio-sobre-a-crise-dademocracia-no-brasil>. Acesso em 10 dez. 2020.

DUARTE, P. A pandemia e o exílio do mundo. Rio de Janeiro: Bazar do Tempo, 2020.

DUARTE, L.; GORGULHO, V (orgs.). No tremor do mundo: ensaios e entrevistas à luz da pandemia. Disponível em: https://cobogo.facileme.com.br/catalogo/literatura/no-tremor-do-mundo-ensaios-e-entrevistas-luz-dapandemia. Acesso em 10 dez. 2020.

GUIMARÃES, M. P. Quarenta e quatro em quarentena: conversas com Miguel Pinto Guimarães. Disponível em: <https://www.amazon.com.br/Quarenta-Quatro-Quarentena-Conversas-Guimarães/dp/6555601329.> Acesso em 10 dez. 2020.

GRUPO GALPÃO. Histórias do confinamento. Disponível em: <https://www.grupogalpao.com.br/historias-deconfinamento-estreia/>. Acesso em 10 dez. 2020.

HALBWACHS, M. La mémoire collective. Paris: Presses Universitaires de France, [1950] 1968.

HUYSSEN, A. Seduzidos pela memória. Rio de Janeiro: Aeroplano, 2000.

Culturas do passado-presente: modernismos, artes visuais, políticas da memória. Rio de Janeiro: Contraponto; Museu de Arte do Rio, 2014.

INUMERÁVEIS. Memorial dedicado à história de cada uma das vítimas do coronavírus no Brasil. Disponível em: <https://inumeraveis.com.br>. Acesso em 10 dez. 2020.

IZEL, A. Cliques A distância. Disponível em: <https://www.correiobraziliense.com.br/impresso/2020/06/2839353cliques-a-distancia.html>. Acesso em: 10 nov. 2020. 
KALININA, E. What do we talk about when we talk about media and nostalgia? Medien \& Zeit, v. 4, p. 6-15, 2016. Disponivel em: <https://medienundzeit.at/wp-content/uploads/2017/02/MZ-2016-4-online-ed.pdf>. Acesso em: 05 jul. 2020.

KEIGHTLEY, E.; PICKERING, M. The Modalities of Nostalgia. Current Sociology, v. 54, n. 6, 919-941, 2006. https://doi.org/10.1177/0011392106068458

LANDWEHR, A. Nostalgia and the turbulence of times. History and Theory, v. 57, n. 2, 251-268, 2018. https:// doi.org/10.1111/hith.12060

MANOVICH, L. 0 Banco de Dados. Revista Eco Pós: arte, tecnologia e mediação. v. 18, n. 1, 2015. Disponível em: <https://revistaecopos.eco.ufrj.br/eco_pos/article/view/2366> Acesso em: 23 jan. 2020.

MARQUES, L.; BORGES, A. Coronavírus e as cidades no Brasil: reflexões durante a pandemia. Disponível em: $<$ https://www.amazon.com/Coronav\%C3\%ADrus-cidades-Brasil-reflexões-Portuguese-ebook/dp/B087LWTKMZ>. Acesso em 10 dez. 2020.

MCCOMBS, M. E. Setting the agenda: The mass media and public opinion. Cambridge, UK: Polity Press, 2004.

MCCOMBS, M. E., SHAW, D. L. The agenda-setting function of mass media. Public Opinion Quarterly, v. 36, n. 2, p. 176-187, 1972.

NIEMEYER, K. Introduction. In: NIEMEYER, K. Media and Nostalgia: yearning for the past, present and future. London: Palgrave MacMillan, 2014. p. 1-23.

NORA, P. Entre memória e história: a problemática dos lugares. (Trad. Yara Khoury). Projeto História, São Paulo, n. 10, p. 7-28, dez. 1993.

NORMAN, D. Design emocional. Rio de Janeiro: Rocco, 2008

OBJETOS DA QUARENTENA. Disponível em: <https://lembrar.espm.br/projetos/objetos-da-quarentena>. Acesso em 28 dez. 2020.

REPOSITÓRIO COVID-19. Cartografias subjetivas do isolamento. Disponível em: <https://repositoriocovid19. unb.br/repositorio-projetos/cartografias-subjetivas-do-isolamento-repensando-os-afetos-os-deslocamentose-cidade-em-tempos-de-pandemia/>. Acesso em 20 dez. 2020.

SANTA CRUZ, L. Memórias na roda: os usos do passado pela economia criativa. In: PINHEIRO, M.; MACHADO, M. (org.). Recortes do contemporâneo: mediações socioculturais. Rio de Janeiro: Mórula, 2020. p. 99-115.

SARLO, B. Tempo passado. Cultura da memória e guinada subjetiva. Belo Horizonte: Companhia das Letras; Editora da UFMG, 2007.

SCHWARCZ, L. M.; STARLING, H. A bailarina da morte: a gripe espanhola no Brasil. São Paulo: Companhia das Letras, 2020.

SEDIKIDES, C. et al. To nostalgize: mixing memory with affect and desire. Advances in Experimental Social Psychology, v. 51, n. 1, 189-273, 2015. https://doi.org/10.1016/bs.aesp.2014.10.001

SILVEIRA, F. L. A.; LIMA FILHO, M. F. Por uma antropologia do objeto documental: entre a "alma das coisas" e a coisificação do objeto. Horizontes Antropológicos, Porto Alegre, ano 11, n. 23, p. 37-50, jan.jjun. 2005.

SOUSA GABRIEL, R. 'História e Memória vivem às turras' diz antropóloga e historiadora Lilia Moritz Schwarcz. O Globo, 27 de julho de 2019. Disponivel em: <https://oglobo.globo.com/cultura/historia-memoria-vivem-asturras-diz-antropologa-historiadora-lilia-moritz-schwarcz-23683009>. Acesso em: 27 jul. 2019.

WALLACE, R. Pandemia e agronegócio: doenças infecciosas, capitalismo e ciência. Disponível em: <https:// www.editoraelefante.com.br/produto/pandemia-e-agronegocio/>. Acesso em 10 dez. 2020. 